\title{
WAS THERE REALLY A HAWTHORNE EFFECT AT THE HAWTHORNE PLANT? AN ANALYSIS OF THE ORIGINAL ILLUMINATION EXPERIMENTS
}

\author{
Steven D. Levitt \\ John A. List \\ Working Paper 15016 \\ http://www.nber.org/papers/w15016
NATIONAL BUREAU OF ECONOMIC RESEARCH
1050 Massachusetts Avenue
Cambridge, MA 02138

May 2009

Thanks to Sonia Jaffe, Andrew Hogue, and Colin Spitz for incredible research assistance. Financial support came from the National Science Foundation and the Sherman Shapiro Research Fund. The views expressed herein are those of the author(s) and do not necessarily reflect the views of the National Bureau of Economic Research.

NBER working papers are circulated for discussion and comment purposes. They have not been peerreviewed or been subject to the review by the NBER Board of Directors that accompanies official NBER publications.

(C) 2009 by Steven D. Levitt and John A. List. All rights reserved. Short sections of text, not to exceed two paragraphs, may be quoted without explicit permission provided that full credit, including $\odot$ notice, is given to the source. 
Was there Really a Hawthorne Effect at the Hawthorne Plant? An Analysis of the Original Illumination Experiments

Steven D. Levitt and John A. List

NBER Working Paper No. 15016

May 2009

JEL No. A0,C91,C92,C93,D03,L22

\begin{abstract}
The "Hawthorne effect," a concept familiar to all students of social science, has had a profound influence both on the direction and design of research over the past 75 years. The Hawthorne effect is named after a landmark set of studies conducted at the Hawthorne plant in the 1920s. The first and most influential of these studies is known as the "Illumination Experiment." Both academics and popular writers commonly summarize the results as showing that every change in light, even those that made the room dimmer, had the effect of increasing productivity. The data from the illumination experiments, however, were never formally analyzed and were thought to have been destroyed. Our research has uncovered these data. We find that existing descriptions of supposedly remarkable data patterns prove to be entirely fictional. There are, however, hints of more subtle manifestations of a Hawthorne effect in the original data.
\end{abstract}

Steven D. Levitt

Department of Economics

University of Chicago

1126 East 59th Street

Chicago, IL 60637

and NBER

slevitt@midway.uchicago.edu

John A. List

Department of Economics

University of Chicago

1126 East 59th

Chicago, IL 60637

and NBER

jlist@uchicago.edu 


\title{
Was there Really a Hawthorne Effect at the Hawthorne Plant? An Analysis of the Original Illumination Experiments
}

\begin{abstract}
"The experiments started with, continued with, and ended with attention focused on one thing and one thing only, what people do. This was the new procedure and it was revolutionary, in the same way that Galileo's or Mendel's procedure was revolutionary in the science of their time." (Hart, 1943)

"In the history of science, certain contributions stand out as signal events in the sense that they influence a great deal of what follows. The Hawthorne Experiments exemplify this phenomenon in the field of industrial work and have been the subject of serious subsequent commentary and reanalysis." (Bloombaum, 1983)
\end{abstract}

When the National Research Council initiated a set of experiments at Western Electric's Hawthorne Plant in Cicero, Illinois in 1924, its objective was to answer a narrow question: does better lighting enhance worker productivity? The results of these experiments, however, have had a profound influence on research in the social sciences ever since. According to Blalock and Blalock (1982, p. 72), to the surprise of the researchers, "each time a change was made, worker productivity increased.....As a final check, the experimenters returned to the original unfavorable conditions of poor lighting....Seemingly perversely, productivity continued to rise.” Spurred by these initial findings, a series of experiments were conducted at the plant over the next eight years. New empirical results reinforced the initial findings. Freedman (1981, p. 49) summarizes the results of the next round of experiments as follows: "Regardless of the conditions, whether there were more or fewer rest periods, longer or shorter workdays...the women worked harder and more efficiently."

From these two sets of experiments came the "Hawthorne effect," and the original illumination studies are commonly recognized among the most influential experiments in social science, helping to spawn the development of a new field of study-Industrial Psychology. Their influence extends well beyond academic circles, as illustrated by Peters and Waterman's 
(1982, pp. 5-6) business writing: "For us, the very important message of the research...is that it is attention to employees, not work conditions per se, that has the dominant impact on productivity (Many of our best companies, one friend observed, seem to reduce management to merely created 'an endless stream of Hawthorne effects')."

In this paper, we revisit the illumination studies. While these experiments represent key early evidence of the Hawthorne effect, the actual data have never been examined and experts thought that they were destroyed. In fact, however, we discovered that the original data from the illumination experiment do exist, preserved in two library archives. Our analysis of the newly found data reveals little evidence to support the existence of a Hawthorne effect as commonly described; i.e., there is no systematic evidence that productivity jumped whenever changes in lighting occurred. On the other hand, we do uncover some weak evidence consistent with more subtle manifestations of Hawthorne effects in the data. In particular, output tends to be higher when experimental manipulations are ongoing relative to when there is no experimentation. Also consistent with a Hawthorne effect is that productivity is more responsive to experimenter manipulations of light than naturally-occurring fluctuations.

We conclude that the evidence for a Hawthorne effect in the studies that gave the phenomenon its name is far more subtle than has been previously acknowledged. Although a parallel is often drawn between the Hawthorne effect and the Heisenberg Uncertainty Principle, our analysis highlights a critical distinction: unlike in quantum mechanics, the Hawthorne effect is not a guaranteed methodological heuristic. Rather, its presence and magnitude depend heavily on economic and psychological features of the environment that can only be understood with further theoretical and empirical modeling. 


\section{Experimentation at the Hawthorne Plant}

The Western Electric Company was the monopoly supplier of telephone equipment to AT\&T in the 1920s. Western's "Hawthorne Works" factory, located in the suburbs of Chicago, was the main supplier for this contract. The Hawthorne plant was considered to be one of the most advanced manufacturing facilities in America at the time, and employed roughly 35,000 people, mainly first- and second-generation immigrants (Gale, 2004). Always open to new techniques to improve efficiency, officials of Western agreed to collaborate with the National Research Council's Committee on Industrial Lighting, which had expressed interest in testing the impact of improved lighting on productivity. The NRC committee included an impressive collection of prominent engineers, including Thomas Edison as its honorary chairman.

Western Electric dispatched two engineers, George Pennock and Clarence Stoll to the Hawthorne plant from 1924-1927 to oversee the experiments in concert with members of the NRC committee (Gale, 2004). These experiments, which are summarized in Figure 1, are known as the "illumination experiments" because they varied the amount of light in the workplace to study how such variation influenced productivity. Figure 1 provides a timeline summarizing the various phases of the illumination experiments, noting for each department the periods during which light was varied experimentally, as well as the periods when output was recorded. Workers in these three departments were women who primarily assembled relays and wound coils of wire, and their output was measured as units completed per unit of time. ${ }^{1}$

\footnotetext{
${ }^{1}$ A relay was a switching device activated in the telephone exchange as each number was dialed. It took about a minute's worth of work to assemble a single relay.
} 


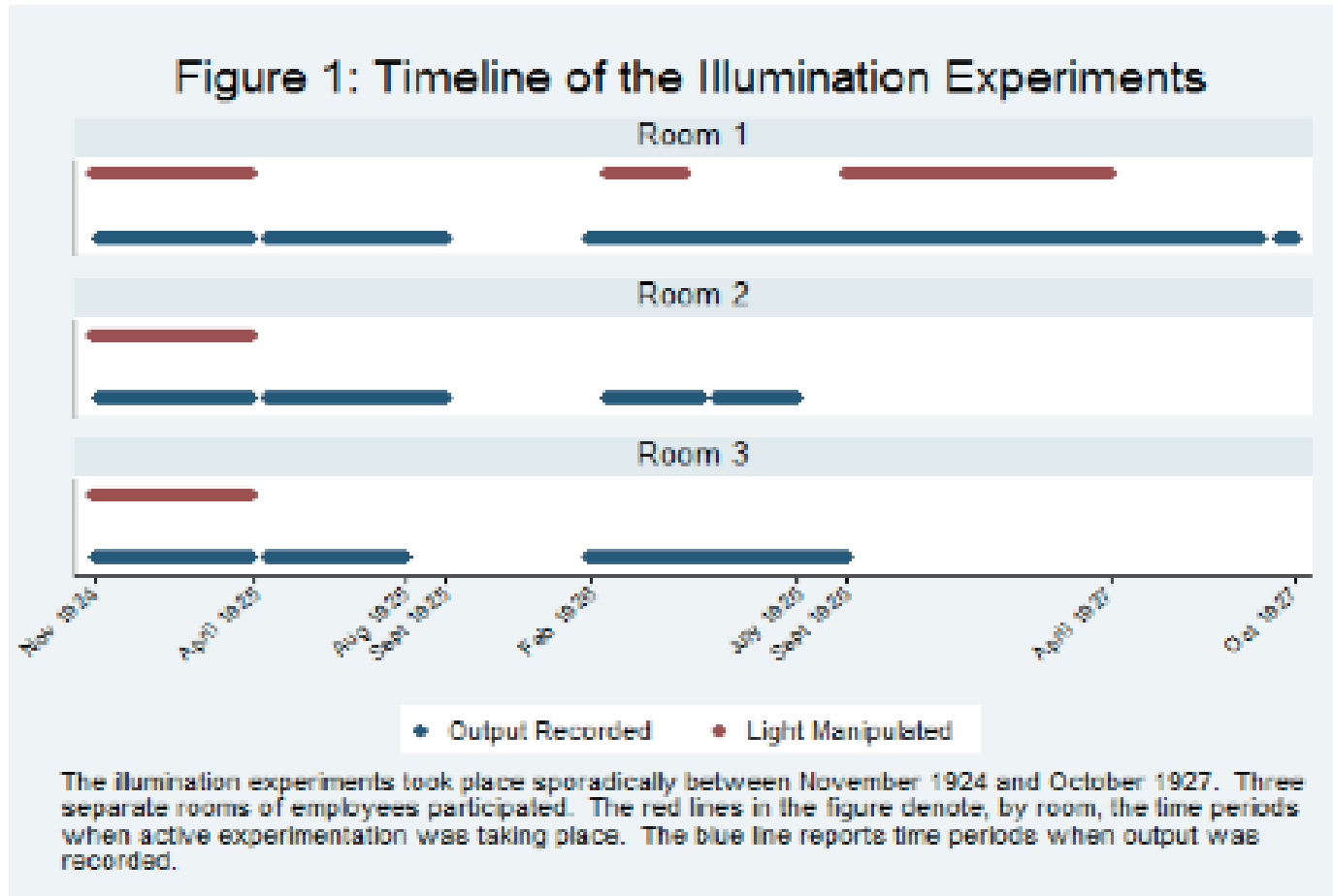

As Figure 1 shows, the first wave of the experiment lasted from November 1924 through April 1925 and involved all three departments. During the summer months there was ample natural light and light recording (and manipulation) was suspended, although output continued to be reported in all three departments. After the summer ended there was a period of time during which no data were recorded (not even output). In February 1926, light manipulation experiments resumed, but only in one of the three rooms. Although there was no experimentation, output was recorded in the other two rooms through the end of the summer of 1926. The Fall of 1926 saw continued lighting experiments in the first room, but data from the other two rooms were no longer reported. The experiments culminated with the most radical experimental manipulations: workers in the first room were dispatched to a room where windows were taped black to have their output monitored under controlled artificial lighting conditions (see Mayo, 1933, pp. 55-56 or Roethlisberger and Dickson, 1939, pp. 14-18, and Gillespie, 1991, 
for more complete accounts). April 1927 marked the end of the illumination experiments, although researchers continued to monitor output in the first room through October 1927.

Unfortunately, data from these illumination experiments were never examined and summarized appropriately, and are broadly believed to have been destroyed. Rice (1982) laments this fact by noting that "the original [illumination] research data somehow disappeared." Gale (2004, p. 439) reinforces this notion by stating that "these particular experiments were never written up, the original study reports were lost, and the only contemporary account of them derives from a few paragraphs in a trade journal."2 Gillespie (1991, pp. 46-47) speculates that the reason the experiments were not written up was due to the fact that the findings did not assuage industry: "the final report would have recommended a basic lighting level of 7 to 10 foot candles....(which)....clearly failed to satisfy the electrical industry's expectations that the research would provide the scientific justification....for higher levels of illumination."

Following on the heels of the illumination studies, a series of further experiments were undertaken. Western Electric brought in academic consultants, most prominently Elton Mayo, in 1928. Experiments were carried out on workers whose jobs were to make relays, split mica, and assemble telephones. The experiments lasted until June 1932, when the women in the test room received their notices due to the poor economy. ${ }^{3}$ The market crash led to one in ten US phones to be disconnected in 1932 , leading to an $80 \%$ decrease in Western Electric's profits.

This second series of experiments provided a wealth of data, summarized in Mayo (1933). His findings have been interpreted as suggesting that individuals are more productive when they know that they are being studied. Importantly, together with the illumination studies,

\footnotetext{
${ }^{2}$ The trade journal article to which Gale refers is authored by Snow (1927), and as Gale correctly notes it only provides a brief description of the experiment.

${ }^{3}$ Except the most exceptional worker, Jennie Sirchio, who worked in the office for a few months before being let go (Gale, 2004).
} 
these experiments lead to a new understanding of the workplace as a system that was first and foremost social, and composed of several interdependent parts. In this manner, both sets of experiments have served to influence dramatically research in organizational development and behavior, leadership, human relations, and workplace design. Carey (1967) describes their influence as follows: "There can be few scientific disciplines or fields of research in which a single set of studies...has exercised so great an influence.”

\section{A Data Discovery}

Even to the most conservative eye the Hawthorne experiments have proved seminal, yet a prominent piece of the puzzle — data from the illumination experiments - has been unfortunately missing. While most believed the data had been destroyed, we were able to trace the data to a microfiche room in a small library in Milwaukee, WI. At this location, however, we only found records for one of the three departments included in the illumination experiments. Further inquiry lead us to a second forgotten archive maintained in Boston, which contained the records for the other two departments involved in the experiments. To our best knowledge, these illumination data have never previously been coded and statistically examined. ${ }^{4}$

Figure 2 shows how light varied over time in Room 1, where the primary experimental manipulation of illumination occurred. Figure 2 reports both the average levels of natural and artificial light over time. Natural light varies with the seasons and is not manipulated by the experimenters, except at the end of the study when the windows were blackened so there was no natural light. The original lighting system in place at the beginning of the experiments provided

\footnotetext{
${ }^{4}$ The illumination data were presented graphically. We extracted the information from the graphs and placed it into spreadsheet form. The raw data and summary statistics for all variables used in this analysis are available from the authors on request. In addition to the illumination data, we also discovered relay data at the daily level for the first thirteen periods of the second round of experiments, thus we are able to extend previous research on these data (e.g., Jones, 1992) by analyzing for the first time the daily data generated by the second set of experiments. We briefly discuss these results below.
} 
4 foot candles of artificial light. The first year of manipulations ranged from this baseline level up to 36 foot candles of artificial light. The second year's experiments used the same range of variation of artificial light, but the third year's experiments differed in that all natural light was eliminated. In this last period, the experimenters started with 11.5 foot candles of artificial light and incrementally lowered light until it reached only 1.4 foot candles (for just one day) before being increased to 11 foot candles. The illumination experiments ended shortly thereafter.

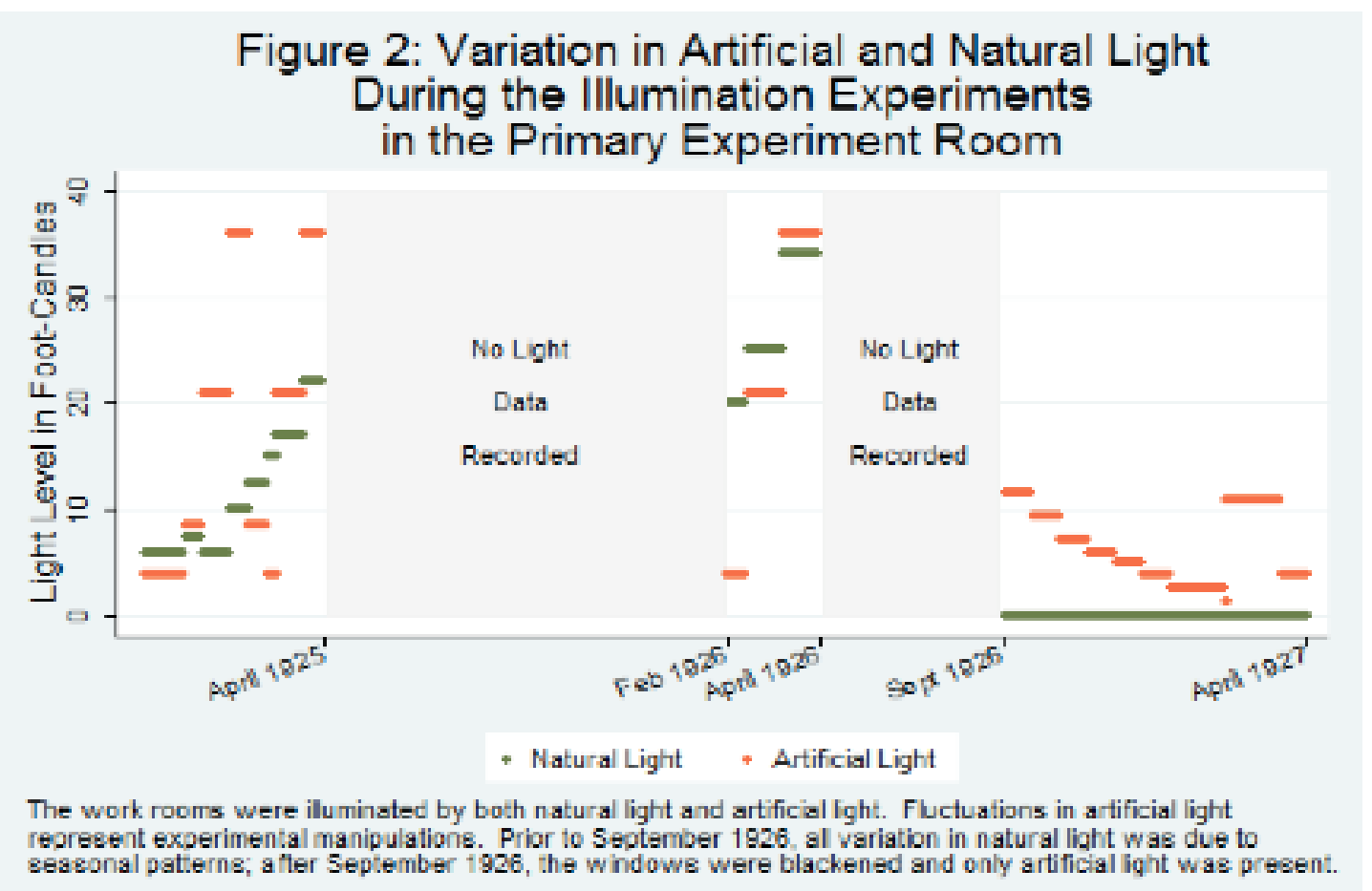

All lighting changes occurred on Mondays so that facility employees would have ample time to alter the lighting arrangements on Sunday, which was the only day of the week that the factory was not in operation. Importantly, at the start of each new experimental period workers were made aware of the experimental changes (see, e.g., Gillespie (1991)).

Figure 3 shows how output varied over time in each of the three rooms. Productivity changes in the three rooms follow a very similar pattern in the first year of the study. Output initially rises sharply and steadily, reaching a peak roughly 10 percent above the baseline 
productivity prior to the start of the experiment. After experimentation is temporarily halted in April of the first year, output declines from its peak, but remains above the baseline level. The productivity gains observed in this first year in the experimental group appear to be large relative to the rest of the Hawthorne plant. Using information from annual company reports from the 1920s, we estimate that output per worker for the plant as a whole increased 1.4 percent per year over the period the Illumination Experiments were active.

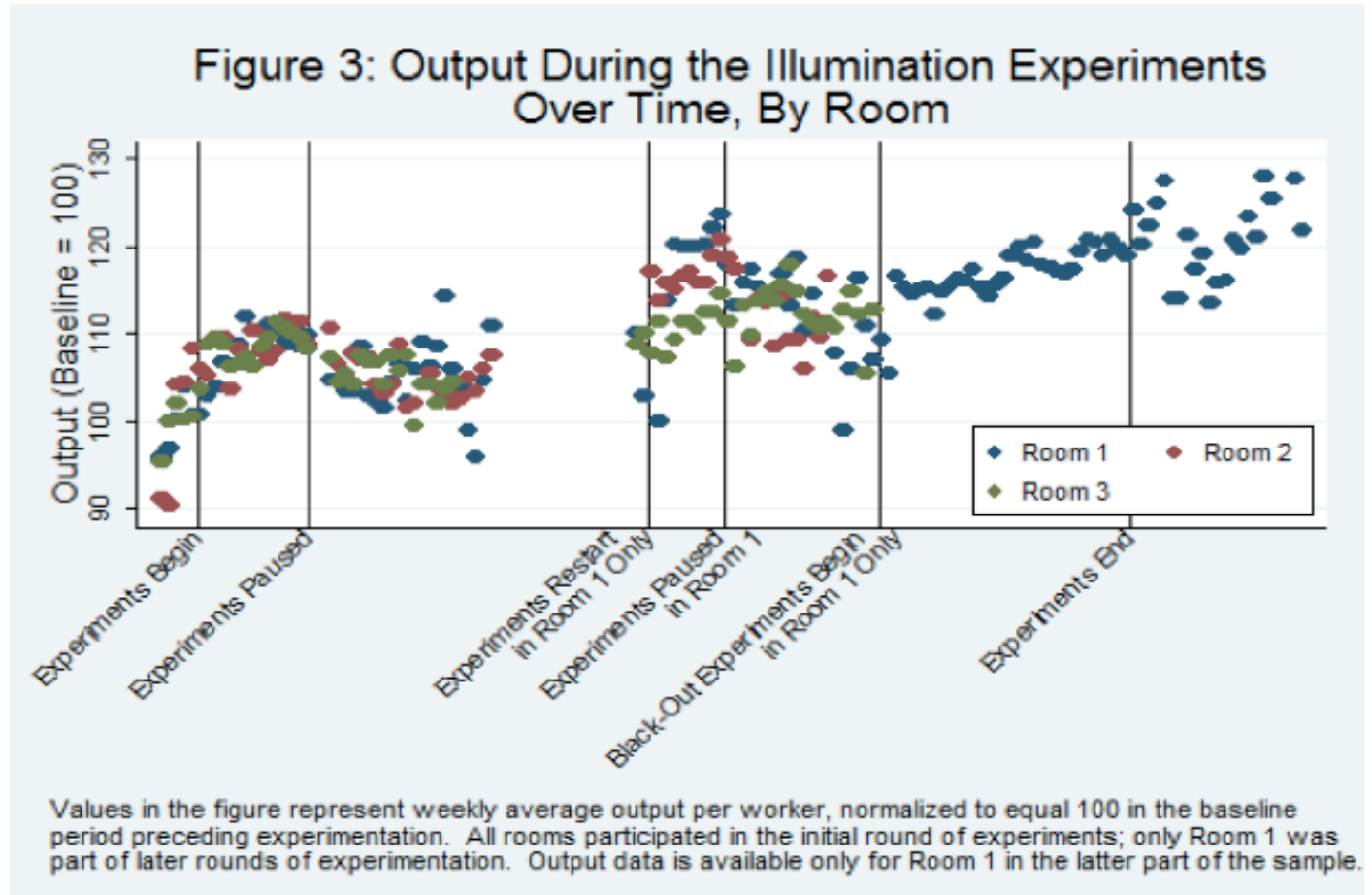

Accordingly, in isolation, the first year's experiences appear to validate the notion of a Hawthorne effect: output rises in response to experimentation and gains fade when the experiments subside. The later years of data, however, pose important challenges to that simple interpretation. Only room 1 was subjected to experimental variation in the second round of experiments (the period bracketed by the third and fourth vertical lines in Figure 3). Room 1 did experience large productivity gains during this time (with output peaking around 20 percent above the pre-experimental baseline), but room 2 (and to a lesser extent room 3) also saw 
substantial increases in output over this interval of time despite the fact that those workers were no longer included in the experiment. When experimentation in room 1 was temporarily suspended for the second time (the period between vertical lines four and five), output in all three rooms declined, just as it had in the previous summer.

This data pattern suggests that the decline reflects a seasonal regularity (lower summer productivity), rather than a response to ceasing experimentation. In the final two periods shown in Figure 3, output was tracked only for room 1, making it difficult to estimate the experimental impact. Output steadily increased during this last phase of experimentation, rose sharply when the experiments stopped, fell sharply during the following summer, but then rebounded to alltime highs towards the end of the sample period when no experimentation was ongoing.

Figure 4 presents higher frequency data to test the common assertion that output increased immediately in response to experimental manipulation of the work environment. Figure 4 plots average daily output in the five days preceding an experimental change and in the five days after a change. All lighting changes were instituted on Mondays. Because output varies systematically by day of the week, we also report the output patterns for the ten days surrounding Mondays in which there was no change in experimental conditions for purposes of comparison. The gap between these two lines reflects a systematic response of output to variations in lighting. 


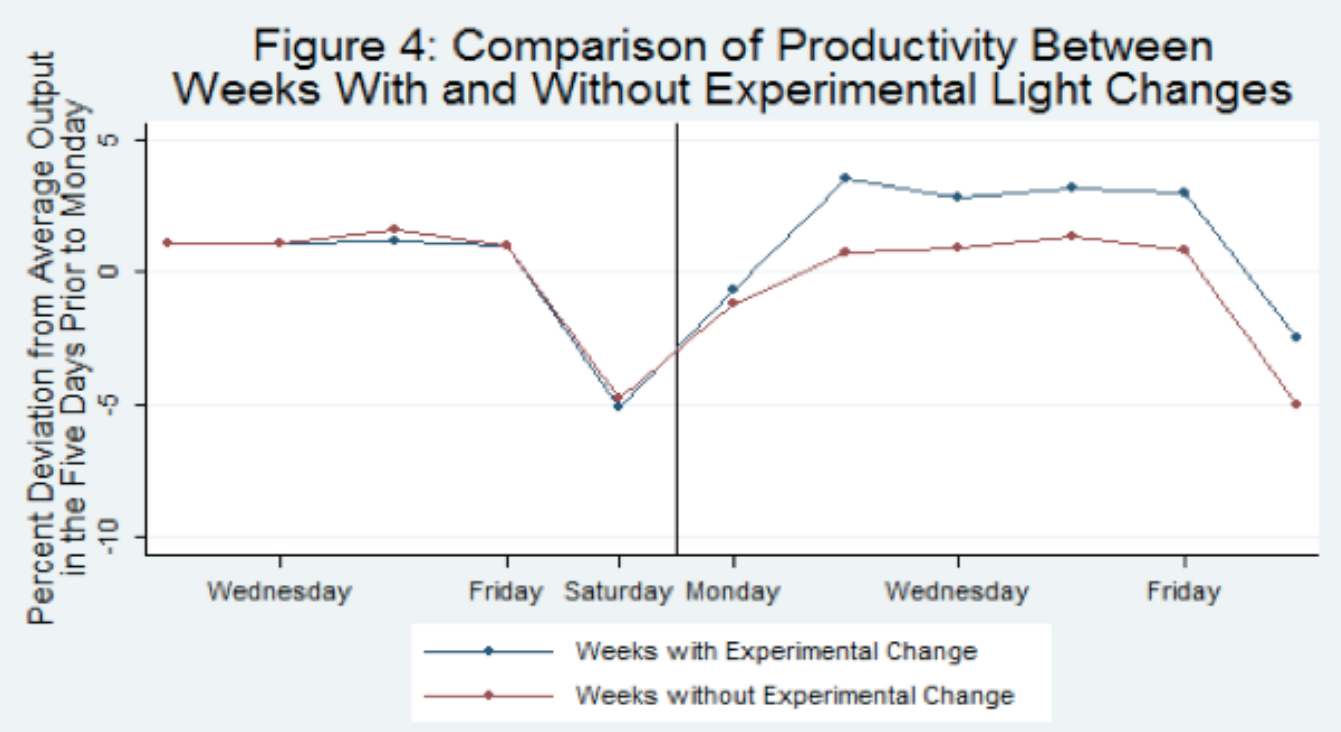

This figure presents daily fluctuations in output per worker. The blue line reflects weeks in which light was experimentally altered. For purposes of comparison, output fluctuations are also shown for weeks in which no experimental change occurred. All lighting changes took effect on Mondays, as denoted by the vertical line. Values in the figure are percent deviations from the average output in the five days preceding the Monday shown in the figure.

For both lines we have normalized output around the average productivity in the preceding five days. Output rises sharply on Mondays when the amount of artificial light is altered, but a comparison to Mondays on which no experimental lighting change is introduced reveals that an identical pattern is present on those days as well. The dominant patterns in the data are driven by within-week cycles - Saturday output is very low; Monday output is less than other weekdays - not by changes in lighting. While output is no higher on the day of the lighting change, output is slightly higher 2-5 days after an experimental change in the raw data. ${ }^{5}$

While as a whole the raw data patterns do not provide much evidence to support the Hawthorne effect hypothesis, in order to more formally analyze these issues we estimate regression models that are variations on the following theme:

$$
\text { Output }_{r t}=\delta_{1} E_{r t}+\delta_{2} E_{r t-1}+\beta_{1} t+\beta_{2} t^{2}+\lambda_{r}+X_{r t} \Phi+\varepsilon_{r t}
$$

\footnotetext{
${ }^{5}$ Dividing experimental changes in lighting conditions into those that are positive (i.e. light levels are increased) and negative (light levels are lowered) yields patterns that are similar.
} 
where $r$ and $t$ index a room and time, respectively. $E$ is an indicator variable reflecting whether there was an experimentally driven change in artificial light on the day in question. We estimate effects for the day of a change and the following day. We control for both linear and quadratic trends in output over time, as well as room fixed-effects. $X$ is a vector of controls that includes weather conditions, indicators for the day of the week and the month, as well as indicators for days before and after a work-canceling holiday, and days in which the inputs were denoted as defective. We also include the frequency with which output is checked and whether workers are located in their original room in the vector of controls. In some specifications we add room*month*year interactions so that treatment effect identification comes solely from comparisons of observations in the same room, month, and year.

The coefficients of primary interest from the estimation are presented in the top panel of Table 1. Column 1 include all control variables except the room*month*year interactions, which are added in column $2 .^{6}$ Columns 1 and 2 in Panel A contain the results the coefficient associated with implementing an experimental lighting change on that day. Columns 1 and 2 differ only in that Column 1 excludes month-year interactions as controls, whereas Column 2 includes month-year interactions. In both columns we find statistically insignificant immediate responses in output to experimental changes in lighting. The point estimate is negative on the first day light is changed and positive on the following day. The combined impact is negative, but close to zero. Note that these results differ somewhat from the raw data presented in Figure

\footnotetext{
${ }^{6}$ Estimated coefficients on these control variables are not presented in Table 1 for parsimony, but full results are available upon request. The trend in output over time is positive, but concave. The estimated coefficients on the control variables are intuitive, and imply that output responds positively to light, negatively to high temperatures, and is low after holidays, when the inputs used are defective, and when the workers are moved to a new room.
} 
4, where experimental changes appear to increase output slightly. After controlling for other important factors, this relationship disappears. ${ }^{7}$

Table 1

Regression Analysis of Experimentation with Lighting on Output

Dependent Variable: Daily Output per Worker $($ Baseline $=100)$

Panel A: Immediate Response of Output to Experimental Variation

\begin{tabular}{lcc}
\hline Day of Experimental Change & $(1)$ & $(2)$ \\
& -1.117 & -1.323 \\
& $(0.80)$ & $(0.75)$ \\
Day after Experimental Change & 0.984 & 0.812 \\
& $(0.80)$ & $(0.74)$ \\
R-squared & 0.69 & 0.75 \\
Includes Controls? & Yes & Yes \\
Includes Room-Month-Year Interactions? & No & Yes
\end{tabular}

$\underline{\text { Panel B: Long-Term Response of Output to Experimental Variation }}$

\begin{tabular}{lcc}
\hline Pre-experimentation (Baseline) & $(1)$ & $(2)$ \\
& - & - \\
Experimentation Ongoing & 3.154 & $(1.46)$ \\
& $(0.86)$ & 2.743 \\
Experimentation Paused or Completed & -1.187 & $(2.41)$ \\
& $(1.60)$ & 0.75 \\
R-squared & & Yes \\
Includes Controls? & 0.70 & Yes \\
Includes Room-Month-Year Interactions? & Yes & No \\
\end{tabular}

Panel C: Response of Output to Variations in the Level of Artificial versus Natural Light

\begin{tabular}{lcc}
\hline Artificial Light & $(1)$ & $(2)$ \\
& 0.056 & 0.0329 \\
Natural Light & $(0.02)$ & $(0.02)$ \\
& -0.045 & -0.021 \\
& $(0.03)$ & $(0.03)$ \\
R-squared & & 0.77 \\
Includes Controls? & 0.75 & Yes \\
Includes Room-Month-Year Interactions? & Yes & Yes
\end{tabular}

The unit of observation is daily output per worker in a room, normalized to equal 100 in the baseline period. Entries in the table are regression coefficients with accompanying standard errors. All specifications include a standard set of controls for linear and quadratic trends in output, weather conditions, day and week indicators, day-before-holiday and day-after-holiday indicators, defective inputs, variations in output-checking and room fixed effects. Specification (2) also controls for roommonth-year interactions. The number of observations is equal to 1,502 in all specifications. Full regression results are available on request from the authors.

Panel A captures the short-run response of output to experimental manipulations while Panel B reflects longer run responses. Panel $\mathrm{C}$ compares the response of output to artificial versus natural fluctuation in light.

\footnotetext{
${ }^{7}$ If we divide changes in artificial light into those that increase versus decrease light, the only statistically significant coefficient we obtain is a reduction in output on the day of experimental changes when artificial light is increased.
} 
Panel B of Table 1 takes a different approach to testing for the Hawthorne Effect. Rather than focusing on immediate changes in output in response to experimental changes, in these specifications we simply divide all observations into one of three mutually exclusive categories: the baseline period prior to the start of experimentation, times when active experimentation is ongoing, ${ }^{8}$ and times when experimentation has been suspended. We include indicator variables for the latter two of these classifications; thus the period before experimentation begins is the omitted category against which the other effects are measured. The same set of controls employed in Panel A is also included in these regressions. Column 2 adds month-year interactions, which are omitted from column 1.

Results from the specification in Column 1 are supportive of a Hawthorne effect. When experimentation is ongoing, output is 3-4 percent higher than in the pre-experimentation baseline, even after controlling for other factors including linear and quadratic time trends and the amount of light. The primary source of identification in this specification is between room 1 and the other rooms, since room 1 continued with the experiments after they were stopped in the other two rooms.

While a Hawthorne effect is one explanation for the results in Column 1, an alternative story is that output in room 1 was rising for other reasons not controlled for in our data. Consistent with this alternative, when we include room by month and month by year interactions in the specification, the result disappears (Column 2 in Panel B). This implies that there is not an abrupt jump up or down in output associated with turning the experiment on and off (i.e. in months when experimentation comes to an end, there is no significant difference before and after

\footnotetext{
${ }^{8}$ This variable is equal to one in the first round of experimentation in all three rooms and in the later rounds of experimenting for room 1 only.
} 
the switch). Whether the results in the previous column are due to longer term effects of experimentation or are spuriously driven by unobservables remains an open question.

The empirical results presented so far do not exploit the information we have on how total light is composed. One manner in which a Hawthorne effect might manifest itself is with output being more responsive to changes in artificial light than to fluctuations in natural light. The logic for this argument is that workers know that the experimenter does not control fluctuations in natural light which are driven by weather and seasonal changes. Only changes in artificial light are manipulated, and thus if workers are particularly influenced by experimental variation, they should be more responsive to artificial light. In addition, changes in artificial light were brought to the attention of the workers on the morning of the new treatment, whereas weather driven changes in natural light were not reported to the workers. As such, one might even expect to see productivity rise in response to experimentally induced reductions in manmade light if the Hawthorne effect is stronger than any direct impact of reduced light on the production process.

Panel $\mathrm{C}$ in Table 1 presents results that test this new Hawthorne hypothesis. Empirical specifications in Panel $\mathrm{C}$ report results for all observations where data are available on the amount of artificial and natural light. ${ }^{9}$ In Panel C, we follow the previous panels by including our standard set of controls and Column 2 adds month-year interactions. In both Columns 1 and 2, artificial light enters positively (in one case statistically significant but not in the other) whereas natural light is negative and insignificant in both columns. The actual magnitude of the impact of fluctuations in artificial light is not particularly large, however. A one-standard

\footnotetext{
${ }^{9}$ When we do not separate natural and artificial light, but rather combine the two to obtain total light, each footcandle of additional light is associated with a statistically significant, but relatively small, increase of 0.0865 units of output. Thus, a one standard deviation increase in light raises output by 1-2 percent. Yet, adding month by year interactions yields a coefficient that is statistically insignificant and trivial in magnitude.
} 
deviation change in artificial light increases output by less than one percent. While clearly circumstantial, this pattern is directionally consistent with a Hawthorne Effect because the increase in output in response to artificial light is greater than for natural light. ${ }^{10}$

\section{Epilogue}

The Hawthorne Plant studies, and the concept of a Hawthorne effect that emerged from this seminal research, stand among the most influential social science research of the $20^{\text {th }}$ century. The purported influence of observation on measured treatment effects in these experiments has lead to a proliferation of research and methodologies to control for the confounding influence that scrutiny can have (e.g., Cook 1962; Harrison and List 2004). Outside of the academy, results from the Hawthorne studies spawned the human relations movement, considerably influenced employee/employer relations, and remain an important influence on the optimal incentive schemes employed in the workplace.

This study returns to the very evidence that induced this contemporary wave of thought by examining new data that was presumed lost. Ironically, there is little evidence of the type of Hawthorne effect widely attributed to these data when one subjects them to careful analysis. We propose and test a new manifestation of the Hawthorne effect: whether workers differentially respond to natural and man-made light. We find some weak evidence that workers respond more acutely to the experimental manipulations than to naturally occurring fluctuations in light. This coupled with the fact that there is some evidence that output was higher during times of experimentation represent our strongest evidence of a Hawthorne effect in the original Hawthorne illumination studies.

\footnotetext{
${ }^{10}$ As noted earlier, we also discovered data at the daily level in the library archives for the first thirteen periods of the second round of experiments. The results obtained are in the spirit of Jones (1992), and consistent with our analysis of the illumination data: we find little support for the Hawthorne effect when the data are properly interpreted. We find, however, that a naïve misreading of the data might lead someone to falsely conclude that a Hawthorne effect is present.
} 


\section{References}

Blalock, A.B. \& Blalock Jr., H.M. (1982). Introduction to social research. Englewood Cliffs, N.J.: Prentice-Hall.

Bloombaum, M. (1983). The Hawthorne experiments: a critique and reanalysis of the first statistical interpretation by Franke and Kaul. Sociological Perspectives, January, 26(1), 71-88.

Carey, A. (1967). The Hawthorne studies: a radical criticism. American Sociological Review, June, 32(3), 403-416

Cook, D.L. (1962). The Hawthorne effect in education research. Phi Delta Kappan, 44, 116-122.

Freedman, J.L., Sears, D.O., \& Carlsmith, J. M. (1981). Social psychology, $4^{\text {th }}$ ed. Englewood Cliffs, N.J.: Prentice-Hall.

Gale, E.A.M. (2004). The Hawthorne studies - a fable for our times? Quarterly Journal of Medicine, July, 97(7), 439-449.

Gillespie, R. 1991. Manufacturing knowledge: a history of the Hawthorne experiments. New York: Cambridge University Press.

Harrison, G.W. \& List, J.A. (2004). Field experiments. Journal of Economic Literature, December, 42(4), 1009-55.

Hart, C.W.M. (1943): The Hawthorne experiments. The Canadian Journal of Economics and Political Science, May, 9(2), 150-163

Jones, S.R.G. (1992). Was there a Hawthorne effect? The American Journal of Sociology, November, 98(3), 451-468.

Mayo, E. (1933). The human problems of an industrial civilization. New York: The Macmillan Company. 
Peters, T.J. \& Waterman, R.H. (1982). In search of excellence: lessons from America's best-run companies. New York: Harper \& Row.

Rice, B. (1982). The Hawthorne effect: persistence of a flawed theory. Psychology Today, 16, 71-74.

Roethlisberger, F.J. \& W.J. Dickson (1939). Management and the worker. Cambridge, Mass: Harvard University Press.

Snow, C.E. (1927). Research on industrial illumination. The Tech Engineering News, November, 257-282 (intermittingly). 